Supplement of The Cryosphere, 9, 1223-1227, 2015

http://www.the-cryosphere.net/9/1223/2015/

doi:10.5194/tc-9-1223-2015-supplement

(C) Author(s) 2015. CC Attribution 3.0 License.

(c) (i)

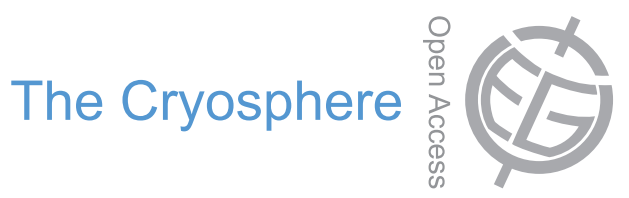

Supplement of

\title{
Brief Communication: Newly developing rift in Larsen C Ice Shelf presents significant risk to stability
}

\section{Jansen et al.}

Correspondence to: D. Jansen (daniela.jansen@awi.de)

The copyright of individual parts of the supplement might differ from the CC-BY 3.0 licence. 
Table 1. List of Landsat images used for this study and the data points of rift extension and rift width (relative to Nov. 2010) derived from the images.

\begin{tabular}{|c|c|c|c|}
\hline \multicolumn{1}{c}{ Date } & Sensor & Width $(\mathbf{m})$ & Extension $(\mathbf{m})$ \\
\hline $\mathbf{2 0 1 0 - 1 1 - 1 5}$ & Landsat 7 & 50 & 0 \\
\hline $\mathbf{2 0 1 1 - 0 3 - 1 4}$ & Landsat 7 & 60 & 445 \\
\hline $\mathbf{2 0 1 2 - 0 1 - 0 5}$ & Landsat 7 & 57 & 3,060 \\
\hline $\mathbf{2 0 1 2 - 0 2 - 2 2}$ & Landsat 7 & 74 & 6,090 \\
\hline $\mathbf{2 0 1 2 - 1 2 - 2 2}$ & Landsat 7 & 85 & 8,330 \\
\hline $\mathbf{2 0 1 3 - 0 3 - 1 2}$ & Landsat 7 & 100 & 8,320 \\
\hline $\mathbf{2 0 1 3 - 1 1 - 0 8}$ & Landsat 8 & 140 & 8,670 \\
\hline $\mathbf{2 0 1 3 - 1 2 - 1 7}$ & Landsat 8 & 168 & 8,810 \\
\hline $\mathbf{2 0 1 4 - 0 1 - 1 1}$ & Landsat 8 & 171 & 8,920 \\
\hline $\mathbf{2 0 1 4 - 0 8 - 3 0}$ & Landsat 8 & 199 & 28,910 \\
\hline $\mathbf{2 0 1 4 - 1 1 - 0 2}$ & Landsat 8 & 204 & 29,230 \\
\hline $\mathbf{2 0 1 4 - 1 2 - 0 4}$ & Landsat 8 & 211 & 29,290 \\
\hline $\mathbf{2 0 1 4 - 1 2 - 1 3}$ & Landsat 8 & 215 & 29,620 \\
\hline $\mathbf{2 0 1 5 - 0 1 - 3 0}$ & Landsat 8 & 222 & 30,000 \\
\hline
\end{tabular}
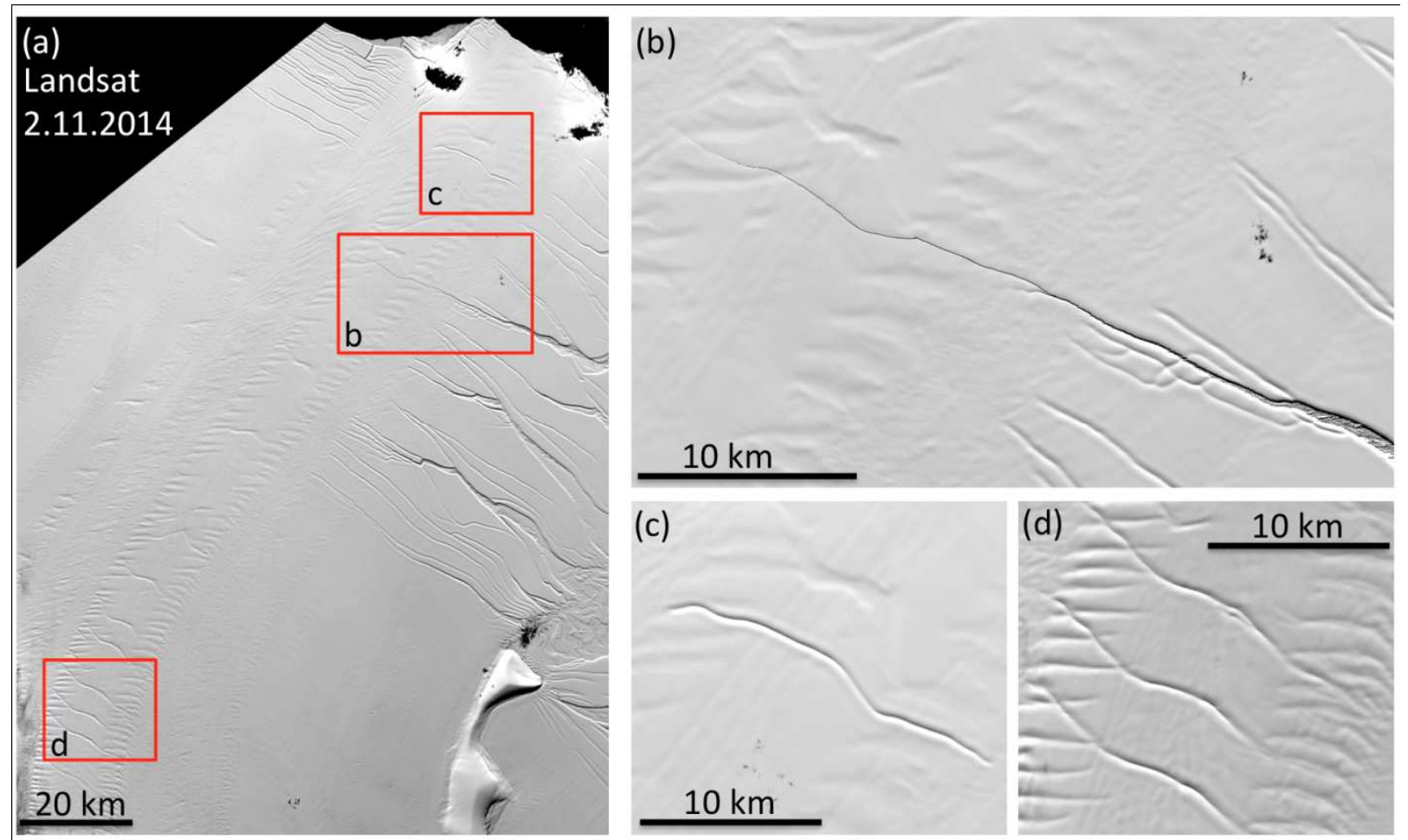

(c)

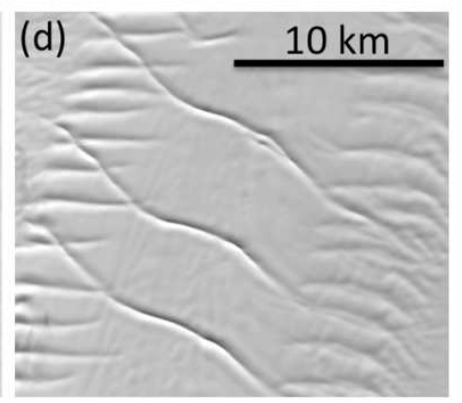

Figure S1: Landat image from November 2014. (a) Overview over the southern part of the Larsen C Ice shelf. Note that the feature in box $c$ is not aligned to features on the southern (right) side of the suture zone. The red boxes indicate the locations of panel s b-d. (b) The new rift is an open fracture, widening towards the south. (c) The feature downstream has a smooth surface and is stalled on both sides. (d) Surface features of basal crevasses originating close to the grounding line. Ground based radar measurements confirmed that they are basal crevasses (Luckman et al., 2012). Note the similarity to the feature shown in (c). 